\title{
Efeitos da hidroterapia no portador de artrogripose múltipla congênita: um relato de caso
}

\author{
Effects of hydrotherapy in patient \\ with arthrogryposis multiple \\ congenital: a case report
}

FisiSenectus . Unochapecó Ano 1, n. 2 - Jul./Dez. 2013 p. $35-45$

\section{Patrícia Galiano}

Graduada em Fisioterapia pela Universidade Regional Integrada do Alto Uruguai e das Missões - Campus Erechim.

\section{Reni Volmir dos Santos}

Fisioterapeuta, mestre, docente da Universidade Regional Integrada do Alto Uruguai e das Missões - Campus Erechim.

\section{Resumo}

Introdução: a artrogripose múltipla congênita é uma síndrome clínica caracterizada por diversas contraturas articulares presentes ao nascimento, sendo usualmente múltiplas e simétricas, sem a presença de déficit intelectual. Hidroterapia, certamente uma das mais agradáveis técnicas no repertório do fisioterapeuta, é utilizada com frequência no tratamento com crianças. Objetivos: verificar se a hidroterapia aumenta a amplitude de movimento e força muscular de paciente portador de artrogripose. Materiais e métodos: estudo de caráter descritivo exploratório, quantitativo, do tipo relato de caso, contou com a participação de um paciente do sexo feminino, 6 anos, escolhida de forma intencional entre os pacientes portadores de artrogripose atendidos na clínica escola da URI - Campus de Erechim. Foi realizada avaliação da amplitude de movimento por meio de goniometria e graduação da força muscular através da escala de Kendall. 0 tratamento consistiu de dois atendimentos semanais, 50 minutos cada, envolvendo atividades de aquecimento, alongamento, fortalecimento e relaxamento, totalizando vinte sessões. Resultados: observou-se uma melhora significativa no aumento de força muscular e amplitude de movimento do paciente.

\section{Palavras-chave}

Artrogripose. Força muscular. Hidroterapia. 


\begin{abstract}
Introduction: Arthrogryposis multiple congenita is a clinical syndrome characterized by multiple joint contractures present at birth, and are usually multiple and symmetrical, without the presence of intellectual deficits. The hydrotherapy, certainly one of the most enjoyable techniques in the repertoire of the physiotherapist, is frequently used in dealing with children. Objectives: verify if the hydrotherapy increases range of motion and muscle strength in patient with arthrogryposis. Materials and methods: a descriptive exploratory study, quantitative account of the type report case, with the participation of a female patient, 6 years, intentionally chosen among patients with arthrogryposis treated at school clinic URI - campus Erechim. The assessment of rage of motion using goniometry and grading of muscle strength using a scale of Kendall. Treatment consisted of two sessions per week, 50 minutes each, involving activities of heating, stretching, strengthening and relaxation, totaling twenty sessions. Results: There was a significant improvement in muscle strength and increase range of the patient.
\end{abstract}

\title{
Keywords
}

Arthrogryposis. Muscle strength. Hydrotherapy.

\section{Introdução}

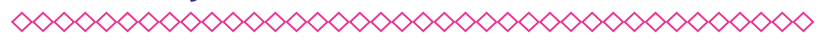

Artrogripose múltipla congênita (AMC) é o nome dado a um grupo de desordens músculo-esqueléticas, caracterizado por contraturas articulares presentes desde o nascimento. As características clínicas principais da AMC, manifestadas no decorrer do desenvolvimento da criança, incluem atrofia muscular, rigidez e deformidades articulares, contratura nos tecidos periarticulares, escassez ou ausência de tecido subcutâneo nos membros que apresentam forma cilíndrica ou fusiforme, alta incidência de luxação em articulações, como quadril e joelho ${ }^{1}$. As deformidades, geralmente, são simétricas e a gravidade destas manifesta-se mais intensamente nas articulações distais ${ }^{2}$.

As contraturas incluem rotação interna de ombros, flexão ou extensão de cotovelo, flexão de punho com desvio ulnar, flexão de quadril com rotação interna de ambas as pernas, ou a chamada "postura de sapo", flexão ou extensão de joelho e deformidades em equinovaro dos pés ${ }^{3}$. A rigidez das articulações é de origem extra-articular em decorrência do encurtamento dos músculos e da contratura das cápsulas articulares. As fibras musculares estriadas encontram-se atrofiadas, ou há substituição muscular por gordura e tecido fibroso. Ocorre espessamento das estruturas periarticulares, que se tornam deformadas, rígidas e inelásticas. A sensibilidade está intacta, bem como a capacidade intelectual e a longevidade, na maioria das crianças portadoras de AMC, encontram-se preservadas, assim como a fala ${ }^{1,4}$.

0 tratamento desta patologia é complexo devido a presença de deformidades comprometendo várias articulações e pela rigidez das estruturas periarticulares, que causam recidivas destas deformidades conforme o paciente cresce e as partes moles não acompanham o crescimento das partes ósseas ${ }^{2}$.

A fisioterapia aquática vem sendo indicada e utilizada por médicos e fisioterapeutas em programas de reabilitação multidisciplinares, principalmente na área ortopédica. Com seu ressurgimento na década passada, houve um grande crescimento e desenvolvimento das técnicas e tratamentos utilizados no meio aquático $0^{5}$. 0 tratamento através da água é agradável e divertido, o que concede um caráter lúdico às atividades e otimiza; desta forma, os resultados da terapia com crianças.

As propriedades físicas, juntamente com o conforto da água aquecida, permitem que aqueles que possuem alguma incapacidade movam-se livremente, de maneira que seria dolorosa ou difícil em solo, facilitando os objetivos físicos e funcionais do tratamento ${ }^{6}$. No processo de reabilitação aquática, os princípios da turbulência como forma de resistência e o uso da flutuabilidade que auxilia os músculos fracos, além da ação das demais propriedades da água, ajudam a melhorar a mobilidade articular e alcançar um reajuste físico. 
Sendo assim, os objetivos do presente estudo foram verificar se a fisioterapia aquática aprimora a força muscular e aumenta a amplitude de movimento dos pacientes portadores de AMC.

\section{Materiais e métodos}

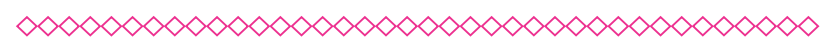

Este estudo caracterizou-se como relato de caso do tipo descritivo exploratório, com uma abordagem quantitativa.

A amostra foi composta por um indivíduo do gênero feminino, 6 anos, com artrogripose, selecionado através de escolha intencional entre os pacientes atendidos na Clínica Escola da Universidade Regional Integrada do Alto Uruguai e das Missões (URI) - Campus Erechim.

A pesquisa desenvolveu-se na sala de Hidrocinesioterapia do Centro de Estágios e Práticas Profissionais da URI (URICEPP). Após, foram contatados os responsáveis pela criança portadora de artrogripose, aos quais foram expostos os objetivos do estudo. Com o parecer favorável, estes assinaram o Termo de Consentimento Livre e Esclarecido e se comprometeram que durante o período de atendimento de fisioterapia aquática a paciente não fosse submetida a outra modalidade de Fisioterapia.

Foram realizadas duas sessões semanais de fisioterapia aquática, com duração de 50 minutos cada, em um período de dez semanas, totalizando vinte sessões. A paciente foi avaliada antes do programa de atendimentos e reavaliada após o período final das dez semanas.

Avaliou-se a amplitude de movimento por intermédio da utilização de goniômetro da marca Trident e a força muscular através da escala de força muscular de Kendall?.

Como procedimento, inicialmente foi realizada a adaptação da paciente ao ambiente aquático. Quando já adaptada, as sessões contemplaram aquecimento, técnicas de alongamento para musculaturas de membros superiores, inferiores e coluna vertebral, amplitude de movimento com exercícios ativos, ativo-assistidos e passivos para as articulações de membros superiores e inferiores, bem como para a mobilidade da coluna ver- tebral, equilíbrio, fortalecimento de forma global (bad ragaz) ou individual para as musculaturas dos segmentos supracitados, e aquisição de marcos motores através do desenvolvimento de atividades lúdicas para apreciação da paciente. Ressalta-se que em todas as sessões foram utilizadas inicialmente técnicas de aquecimento, por intermédio de caminhada (frente, costas, lateral), corrida e saltos. Após eram realizados alongamento dos grupos musculares e exercícios para ganho de amplitude e fortalecimento muscular. Técnicas de correção postural e de equilíbrio foram realizadas em sessões intercaladas, por meio do uso de dispositivos e turbulência da água.

Os escores quantitativos obtidos com o resultado da goniometria e do teste de força muscular foram registrados e analisados por estatística descritiva. Depois disso, para a tabulação e análise descritiva dos dados, foi utilizado o software Microsoft Office Excel 2007.

Esta pesquisa está de acordo com as diretrizes da Resolução 196/1996, do Conselho Nacional de Saúde do Ministério da Saúde, e foi aprovada pelo Comitê de Ética em Pesquisa da Universidade Regional Integrada do Alto Uruguai e das Missões Campus de Erechim, sob o número 095/TCH/10.

\section{Resultados e discussão}

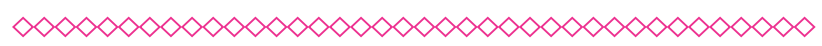

Embora a artrogripose seja caracterizada por várias deformidades nas articulações - como limitação no arco de movimento, rigidez, contratura nas cápsulas articulares e tecidos periarticulares -, a imersão em água morna, associada à cinesioterapia passiva e ativa ${ }^{8}$, levou a uma facilitação no ganho de amplitude de movimento (ADM), na maioria das articulações analisadas, como mostram as tabelas 1 e 2 . Resultados semelhantes foram observados por Carvalho e Santos ${ }^{1}$, em que houve diferença de ADM pré e pós-tratamento, assim como a porcentagem de melhora da mobilidade do membro superior, em que, exceto para extensão do punho direito, todas as articulações avaliadas apresentaram ganho de ADM. Embora tenha sido pequeno, este ganho foi relevante, já que esta articulação se encontrava imóvel. 
Os resultados obtidos no presente estudo, apesar de mínimos, são relevantes quando se trata de artrogripose múltipla congênita, pelo fato desta ser uma patologia caracterizada por rigidez articular globalizada. 0 grau de inteligência normal que os portadores geralmente apresentam e a grande capacidade adaptativa frente às deformidades presentes são pontos facilitadores do tratamento. Sendo assim, qualquer grau de amplitude de movimento que se apresente aumentado, em relação a avaliação inicial, é satisfatório e traz benefícios inimagináveis para os portadores da patologia, principalmente crianças, por possibilitar maior liberdade de movimento para descobrir o ambiente.

De acordo com Ratliffe ${ }^{4}$, a fisioterapia consiste em alongar os tecidos, mobilizar as articulações e incentivar os movimentos ativos visando aumentar a qualidade de vida. Assim, as metas da fisioterapia para a criança com AMC são o ganho de amplitude de movimento ativo e passivo, força adequada para atingir as habilidades funcionais, transição, mobilidade e capacidade para participar das atividades em casa e na escola, assim como na comunidade. A fisioterapia aquática, neste caso, foi iniciada com um programa de exercícios que aumentam o grau de mobilidade das articulações acometidas, em que foram realizados exercícios de forma constante, durante o período em que 0 paciente foi tratado na piscina.

A rigidez articular pode ser atenuada pelo calor da água que causa uma vasodilatação e um aumento da temperatura da pele. A flutuabilidade da água auxilia os movimentos das articulações rígidas em amplitudes maiores com aumento mínimo de dor. 0 uso de boias para conquistar um bom alongamento, juntamente com a técnica segura/ relaxa, seguida de movimentos fisiológicos passivos ou movimentos acessórios passivos, ajudou a obter uma amplitude de movimento extra ${ }^{9}$. Esta melhora pode ser devido ao fato de a água reduzir o estresse sobre as articulações, facilitando os movimentos. Fatores como aumento da temperatura dos músculos, redução do espasmo, relaxamento muscular, melhora da circulação periférica e diminuição da dor podem justificar o ganho de mobilidade observado neste estudo ${ }^{10}$.

Resultados semelhantes foram observados por Silva et al. ${ }^{11}$ em pacientes com osteoartrite de jo- elho, que após 18 semanas de exercícios em água relataram melhora da dor, redução da rigidez articular e melhora da função da articulação do joelho. Diferentemente dos resultados obtidos na realização da goniometria em solo, todos os movimentos de ambos os membros superiores apresentaram aumento de ADM.

No processo de reabilitação aquática, os efeitos fisiológicos da água aquecida, os princípios da turbulência como forma de resistência e o uso da flutuabilidade, auxiliando os músculos fracos, contribuíram para o paciente alcançar um reajuste físico. Na água é muito mais fácil estimular, pois é um meio tridimensional que possibilita ao indivíduo controlar ativamente seu corpo em diferentes posições. Esta vantagem favorece o caminho da plasticidade neuromuscular, pois proporciona diferentes formas de aprendizado. 0 aprendizado no meio líquido facilita, motiva e ajusta as habilidades motoras do indivíduo e torna-se eficaz quando há transferência para o meio terrestre ${ }^{12}$.

Segundo estudos realizados por Burns e Macdonald $^{13}$, a instituição precoce de um regime intensivo de movimentação ativa e passiva e o uso de talas (órteses) é particularmente eficaz, melhorando, de um modo geral, as funções da criança portadora de artrogripose. Secco ${ }^{14}$ e Burns e Macdonald $^{13}$ enfatizam a importância dos exercícios de mobilização articular para manter e/ou melhorar a amplitude de movimento em torno das articulações, além de prevenir o aparecimento de possíveis contraturas. De acordo com estudos realizados, a fisioterapia deve ser baseada em mobilizações das articulações, em alongamento dos tecidos moles e em facilitações de movimentos ativos de membros e do tronco para que então essas crianças possam adquirir habilidades funcionais as quais serão utilizadas para o resto da vida. A criatividade do fisioterapeuta é um fator imprescindível para que o tratamento seja capaz de modificar a qualidade de vida e reabilitar pacientes com artrogripose ${ }^{15}$.

Os exercícios em água aquecida promovem relaxamento muscular, reduzem a sensibilidade à dor e espasmos musculares; diminuem a atuação da força de gravidade, o que facilita o movimento articular; aumentam a força e resistência muscular; melhoram a circulação periférica ${ }^{16}$. Conforme Bates e Hanson ${ }^{17}$, a melhor perfusão tecidual leva 
ao aumento da sensibilidade nas terminações nervosas, com melhora na condução de estímulos e na propriocepção. Isto, aliado aos efeitos antigravitários da água, proporciona melhor tônus muscular e consequente adequação e eficiência na execução de exercícios com menor risco de lesão.

Há evidências de que o ambiente aquático estimula um aumento da propriocepção e do equilíbrio através do aumento de aferências cutâneas e musculares, além de facilitar um aumento de aferências vestibulares. 0 aumento da estimulação somatossensorial (feedback) promove uma elevação dos disparos neurais em um ambiente mais estável, facilita o esforço neuromotor e possibilita maior independência funcional nas atividades no solo. A distensão ou alongamento da pele durante o movimento da água também provoca uma estimulação dos mecanorreceptores, e contribui para uma melhora da propriocepção corporal ${ }^{18,19}$.

Os princípios de treinamento de força usados em atividades baseadas em terra também são usados na realização de exercícios de fortalecimento na água. Enquanto a resistência em terra é fornecida pelo peso e pela gravidade, a resistência na água é fornecida pela turbulência e pela flutuação, e é influenciada pela área de superfície, pela velocidade de movimento e pelo arrasto ${ }^{6}$. Sendo assim, obteve-se manutenção ou aumento de força em todas as articulações estudadas, como é possível perceber nas figuras 1 e 2 , em que se encontra a comparação de força em solo pré e pós-tratamento nas articulações dos membros superiores.

0 exercício resistido no qual uma contração muscular dinâmica ou estática é resistida por força externa, aplicada mecânica ou manualmente, é um quesito imprescindível em um programa de reabilitação, para se promover a saúde e o bem-estar físico e prevenir o risco de lesões. Ele restaura, melhora ou mantém a força, a potência e a resistência muscular, diminuindo a fadiga, entre outros efeitos ${ }^{20}$.

Segundo Campion ${ }^{9}$, o fortalecimento muscular pode ser conquistado por meio do uso de exercícios minunciosamente graduados utilizando a flutuabilidade como assistência, apoio ou resistência. A turbulência como resistência pode ser administrada de modo idêntico pelo aumento da velocidade dos movimentos, tanto alterando o comprimento do braço de alavanca, quanto utilizando equipamentos como boias ou bastões, que podem ser usados de maneira aerodinâmica ou não, alternando, nesse caso, a resistência dos movimentos. As técnicas de Bad Ragaz de padrões de massa dos movimentos, utilizando padrões que agem contra as deformidades e movem as articulações livres de dor, também podem ser empregadas para o ganho de fortalecimento muscular, o que vem ao encontro ao tratamento proposto e realizado, em que foram utilizadas técnicas de Bad Ragaz agindo contra as deformidades, como cita o autor.

Com relação ao grupo de músculos flexores de punho, houve manutenção da força muscular. Em contrapartida, o grupo de músculos extensores de punho apresentou um grau de aumento de força muscular em ambos os membros superiores. Foi possivel observar que flexores e extensores de ambos os punhos não chegaram ao grau máximo de força muscular. 0 punho é uma das articulações mais acometidas da paciente em questão; por este motivo, acredita-se que não foi possível obter o grau máximo de força muscular.

Segundo Chiconelli e Monteiro ${ }^{21}$, esta deformidade ao nível dos punhos e mãos nas crianças portadoras de artrogripose depende basicamente da retração ou má-formação do retinaculum cutis (fáscia mediopalmar e ligamentos natatórios) e da pele digitopalmar (nos casos leves), e também do envolvimento de outros tecidos, tais como tendões, cápsulas e ligamentos (nos casos mais severos). Por isso, na maioria dos casos, caracterizam-se como as articulações mais rígidas e de mais difícil tratamento.

0 ganho de força muscular através da hidroterapia pode ser conseguido por meio da resistência da água ao movimento, o que pode ser incrementado com o aumento da velocidade durante a execução destes e, consequentemente, possibilitar o trabalho muscular. A flutuação é outra propriedade que pode oferecer resistência, e neste caso o movimento deve ser realizado no sentido da superfície para o fundo da piscina. A viscosidade é outro fator que proporciona resistência ao movimento e está intimamente ligada à velocidade, resultando em ganho de força muscular ${ }^{22}$.

Com relação aos membros inferiores, houve aumento de força muscular de todos os grupos 
musculares responsáveis pelos movimentos do quadril, sendo que os únicos grupos musculares que não atingiram grau máximo de força foram os extensores de quadril direito, rotadores internos de quadril direito e rotadores externos de quadril direito e esquerdo, revelando maior déficit de força muscular em quadril direito, conforme observado na figura 3.

Em um estudo realizado por Saviatto ${ }^{23}$, utilizando a hidroterapia com o objetivo de aumentar a força dos músculos responsáveis pelos movimentos do quadril em pacientes submetidos a artroplastia total de quadril, houve ganho de dois graus de força em quatro pacientes e ganho de um grau de força em dois pacientes, sendo que, dos seis pacientes avaliados, quatro atingiram o grau máximo de força muscular no pós-tratamento.

A hidroterapia focaliza uma melhora na condição física do músculo, desenvolvimento de força e resistência em casos de fraqueza muscular, facilitação de músculos paréticos e facilitação da marcha e ortostatismo, permitindo deambulação precoce ${ }^{6,17}$.

Através da analise da figura 4, pode se perceber que houve aumento da força da musculatura de joelho com relação a todos os grupos musculares, sendo que este aumento foi de um grau para flexão de joelho direito e esquerdo e extensão de joelho esquerdo. A extensão de joelho direito apresentou um ganho de força de dois graus. Apesar do ganho de força muscular, apenas o grupo muscular extensor de ambos os joelhos atingiu grau máximo de força.

Segundo Fedrigo ${ }^{24}$, as partes submersas do corpo encontram resistência em todas as direções do movimento, o que requer uma quantidade maior de gasto energético. A água aquecida promove 0 relaxamento dos músculos espásticos antagonistas aos músculos enfraquecidos, exercitando-os. 0 efeito estimulador da água ajuda o paciente a tornar-se mais consciente das partes do corpo que estão em movimento e mecanicamente envolvidas na movimentação.

Candeloro e Caromano ${ }^{25}$ avaliaram o efeito de um programa de hidroterapia na flexibilidade e na força muscular de idosas. Trinta e uma idosas participaram do programa, sendo 16 de hidroterapia e 15 do grupo controle. 0 treino foi realizado em piscina aquecida em temperatura de $32^{\circ} \mathrm{C}$, apli- cado por três meses, três vezes por semana com duração de uma hora, e com exercícios de baixa e moderada intensidade, por intermédio da avaliação do miômetro para mensurar a força muscular e máquina fotográfica para avaliação da flexibilidade. A análise demonstrou melhora estatisticamente significativas na realização das atividades físicas e na amplitude de movimentos e nas articulações dos membros superiores e inferiores. A hidroterapia mostrou-se eficiente para produzir melhora na flexibilidade e na força muscular das idosas, como no presente estudo.

Em um estudo realizado por Veiga ${ }^{25}$, em que foi desenvolvido um protocolo de tratamento hidroterapêutico com uma criança portadora de artrogripose múltipla congênita, obteve-se manutenção do grau de força dos músculos flexores de quadril e de joelho, com exceção dos flexores de joelho esquerdo, que apresentaram um grau de aumento no pós-tratamento.

Com relação ao aumento do grau de força muscular de plantiflexores e dorsilflexores (figura 4), observa-se que houve aumento em ambos os tornozelos no período pós-tratamento, sendo este aumento de um grau para os movimentos de dorsiflexão de tornozelo direito e esquerdo e plantiflexão de tornozelo esquerdo. 0 resultado mais significativo foi em relação a plantiflexão de tornozelo direito, que obteve dois graus de aumento, atingindo o grau máximo de força muscular. Vale destacar que se a fraqueza no pé e no tornozelo permanecesse, o indivíduo teria futuras dificuldades em coordenar o pé durante os passos; assim, 0 corpo necessitaria recrutar um padrão de iniciação proximal, com compensações pelo quadril, de circundução ou de inclinação pélvica, alterando toda a biomecânica da marcha ${ }^{27}$.

Os exercícios aquáticos fornecem aplicação suave de resistência, amplitude completa de movimento e a oportunidade de treinar em várias velocidades. Esses componentes fazem do exercício aquático um excelente método para aumentar resistência e força. A viscosidade é o atrito entre as moléculas de um líquido e que causa uma resistência a um corpo em movimento. Esse fator aumenta em oitocentas vezes a resistência em relação ao ar. É importante para o início da reeducação muscular, na qual grupos musculares podem estar debilitados, necessitando graduar a resistência ${ }^{6,28}$. 
Ornellas et al. ${ }^{29}$ avaliaram, através de um estudo, a reabilitação visando promover uma vida mais independente para o portador da Síndrome Pós-Poliomielite. 0 tratamento foi realizado a um paciente em piscina aquecida com duração de dez semanas, com frequência de duas vezes na semana e duração de 50 minutos, sendo analisado com recursos terapêuticos e aplicação de um questionário com perguntas específicas em relação a sua saúde física e mental. Foi possível constatar uma melhora no seu bem-estar, proporcionando relaxamento muscular, melhora do equilíbrio, redução do quadro álgico, ganho de amplitude de movimento e de força muscular.

Com o aumento da temperatura da água, a viscosidade diminui porque as moléculas estão mais afastadas, o que beneficia músculos pequenos e fracos. A viscosidade torna a água um meio propício para o treino de fortalecimento, porque a sua resistência aumenta à medida que mais força é exercida contra ela, caindo essa resistência a zero quando cessa o movimento ${ }^{6}$.

Durante a imersão, consegue-se uma estabilidade articular somando os efeitos da pressão hidrostática e da viscosidade. Essa estabilidade permite uma melhor consciência corporal e do segmento a ser trabalhado, permitindo um treino com maior segurança e evitando posturas incorretas. Utilizando a força vertical oposta à gravidade fornecida pelo empuxo, podemos auxiliar musculaturas enfraquecidas, que não são capazes de vencer a ação da gravidade, a serem ativadas e fortalecidas. 0 empuxo pode ser utilizado para auxiliar ou dificultar o movimento, dependendo do posicionamento da musculatura a ser trabalhada com relação ao vetor da força gerado por ele. Esses movimentos podem ser refinados com o uso de flutuadores para promover facilitação ou resistência ${ }^{27}$.

Dentre as referências analisadas, não foi possível encontrar estudos que correlacionem a hidroterapia com o fortalecimento muscular de crianças portadoras de artrogripose múltipla congênita, limitando a comparação da pesquisa com estudos similares. Sugere-se a realização de mais pesquisas utilizando o fortalecimento como marcador de função, visando comprovar a eficácia de um treinamento de força muscular por meio da hidroterapia em crianças portadoras desta síndrome.

\section{Conclusão}

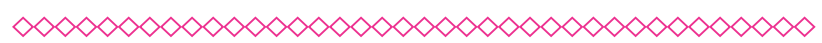

Os resultados obtidos permitem inferir que 0 tratamento através da hidroterapia demonstrou ser benéfico para a portadora de artrogripose múltipla congênita avaliada, no que diz respeito ao aumento da amplitude de movimento articular e no grau de força muscular.

Por ser uma síndrome rara, a ausência de relatos na literatura torna trabalhoso o desenvolvimento dos estudos sobre a AMC. Por outro lado, é um campo aberto para novas investigações, sendo que, se realizado de forma multidisciplinar e não limitado apenas à fisioterapia, pode-se potencializar os ganhos neuropsicomotores.

Assim, o tratamento por intermédio da hidroterapia objetivou avaliar o quanto a criança beneficiou-se com a intervenção fisioterapêutica, mensurando através da goniometria e teste de força muscular, sendo que os resultados obtidos pós-tratamento foram todos clinicamente significativos, o que confere a importância da fisioterapia no tratamento da AMC.

\section{Referências}

$\infty<\infty<\infty<\infty<\infty<\infty<\infty<\infty<\infty<\infty<\infty<\infty<\infty<\infty<\infty<\infty$

\section{Carvalho RL, Santos C E. Efeito da imersão} associado a cinesioterapia na artrogripose. Revista científica UNIFAE. 2008;2(1):10-14.

2. Startman C, Fucs PMMB, Kertzman PF, Kampe PA, Rosseti, FTR. Artrogripose múltipla congênita. Revista ortopedia Brasil. 1995; 30(1):45-52.

3. Tecklin JS. Fisioterapia pediátrica. 3. ed. Porto Alegre: Artmed; 2002.

4. Ratliffe KT. Fisioterapia clínica e pediátrica: guia para a equipe de fisioterapeutas. São Paulo: Santos; 2002

5. Biasoli MC, Machado CMC. Hidroterapia: técnicas e aplicabilidades nas disfunções reumatológicas. Temas de reumatologia clínica. 2006; 7(3):78-87.

6. Ruoti R, Morris D, Cole A. Reabilitação aquática. São Paulo: Manole; 2000. 
7. Kendall FP, Mccreary EK, Provance PG. Músculos: provas e funções. 5. ed. São Paulo: Manole; 2007.

8. Smith DW, Drennan JC. Arthrogryposis wrist deformities: results of infantile serial casting. J Pediatr Orthop B. 2002; 22(1)44-7.

9. Campion MR. Hidroterapia. São Paulo: Manole; 2000.

10. Eversden L, Maggs F, Nightingale $P$, Jobanputra P. A pragmatic randomised controlled trial of hydrotherapy and land exercises on overall well being and quality of life in rheumatoid arthritis BMC Musculoskelet Disorder. 2007; 8(23):1-7.

11. Silva LE, Valim V, Pessanha ACl. Hydrotherapy versus conventional land-based exercise for the management of patients with osteoarthritis of the knee: a randomized clinical trial. Physio Therapy. 2008; 88(1):12-21.

12. Dornelas LF. Técnicas de Hidroterapia em um caso de Jarcho-Levin. Revista Neurociências. 2010; 20(3):1-4.

13. Burns YR, Macdonald J. Fisioterapia e crescimento na infância. São Paulo: Santos; 1999.

14. Secco TF. A atuação da cinesioterapia motora na artrogripose do tipo distal. Revista Lato \& Sensu, 2004; 5(1):136-141.

15. Risarde, SMA. Artrogripose múltipla congênita. Trabalho de conclusão de curso. Universidade Veiga de Almeida, Rio de Janeiro; 2007; 60p.

16. Marins QO. Hidroterapia. 2004 [acesso em 11 jul 2011]. Disponível em <http:/www.wgate. com.br/conteúdo/medicinaesaude.fisioterapia/ alternativa/hidroterapia_watsu.htm>

17. Bates A, Hanson N. Exercícios Aquáticos Terapêuticos. São Paulo: Manole; 1998.

18. Perry J. Gait Analysis: normal and pathological function. New York: McGraw-Hill; 1992.

19. Ciolek $\mathrm{CH}$, Geigle PR. Age and water do mix. Rehabilitation Management. 2002; 5:28-30.

20. Lima APT, Ribeiro IA, Coimbra LMC, Santos MRN, Andrade EN. Mecanoterapia e fortalecimento muscular: um embasamento seguro para um tratamento eficaz. Revista Saúde.com. 2006; 2(2):143-152.

21. Chiconelli JR, Monteiro V. A mão na artrogripose múltipla congênita. Revista ortopedia Brasil. 1994; 29(7):501-504.

22. Marins SR. Síndrome de Down e terapia aquática: possibilidades da influência dos efeitos físicos da água na musculatura estriada esquelética e na postura. Reabilitar. 2001; 10:12 - 20.

23. Saviatto JM. Hidroterapia como método de reabilitação de pacientes submetidos à artroplastia total de quadril. 2006. Trabalho de conclusão de curso. 72p. Graduação em Fisioterapia, Universidade do Sul de Santa Catarina: Tubarão.

24. Fedrigo SC. Análise da atividade elétrica do músculo reto abdominal, após tratamento com o método bad ragaz em paciente com traumatismo cranioencefálico (estudo de caso). 2007. Trabalho de conclusão de curso. 77p. Graduação em Fisioterapia, Faculdade Assis Gurgacz - FAG: Cascavel.

25. Candeloro JM, Caromano FA. Efeitos de um programa de hidroterapia na flexibilidade e na força muscular de idosas. Rev Bras Fisioter. 2007; 11(4):303-309.

26. Veiga CLS. A eficácia da hidroterapia em paciente portador de artrogripose múltipla congênita - estudo de caso. 2006. Trabalho de conclusão de curso. 92p. Graduação em Fisioterapia, Faculdade Assis Gurgacz - FAG: Cascavel

27. Silva JB, Branco FR. Fisioterapia aquática funcional. São Paulo: Artes Médicas; 2011.

28. Martins QO, Rosa FBJ. Hidroterapia. São Paulo, 2004 [acesso em 30 set 2011]. Disponível em: <http://www.wgate.com.br/fisioweb/alternativas. asp $>$.

29. Ornelas E, Machado BBX, Neri AD, Mazetto AA, Navarro FM. A influência da terapia aquática na reabilitação de um portador de síndrome póspoliomielite - relato de caso. Arquivo Ciências Saúde Unipar. 2008; 12(1):55-59. 


\section{Anexos}

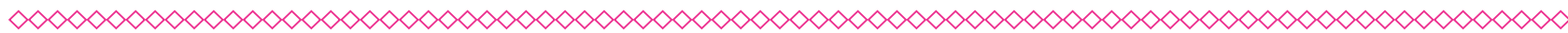

Tabela 1 - Goniometria de membros superiores pré e pós-tratamento

\begin{tabular}{|c|c|c|c|c|}
\hline \multicolumn{5}{|l|}{ Membro superior } \\
\hline Articulação e movimento & \multicolumn{2}{|c|}{ DIREITO } & \multicolumn{2}{|c|}{ ESQUERDO } \\
\hline OMBRO & PRÉ & PÓS & PRÉ & PÓS \\
\hline Flexão & $120^{\circ}$ & $130^{\circ}$ & $90^{\circ}$ & $110^{\circ}$ \\
\hline Extensão & $35^{\circ}$ & $40^{\circ}$ & $30^{\circ}$ & $35^{\circ}$ \\
\hline Abdução & $100^{\circ}$ & $115^{\circ}$ & $90^{\circ}$ & $110^{\circ}$ \\
\hline Adução & $0^{\circ}$ & $0^{\circ}$ & $0^{\circ}$ & $0^{\circ}$ \\
\hline Rotação Interna & $70^{\circ}$ & $80^{\circ}$ & $65^{\circ}$ & $70^{\circ}$ \\
\hline Rotação Externa & $60^{\circ}$ & $60^{\circ}$ & $55^{\circ}$ & $60^{\circ}$ \\
\hline Abdução Horizontal & $70^{\circ}$ & $70^{\circ}$ & $70^{\circ}$ & $70^{\circ}$ \\
\hline Adução Horizontal & $130^{\circ}$ & $135^{\circ}$ & $120^{\circ}$ & $135^{\circ}$ \\
\hline \multicolumn{5}{|l|}{ COTOVELO } \\
\hline Flexão & $90^{\circ}$ & $110^{\circ}$ & $80^{\circ}$ & $100^{\circ}$ \\
\hline Extensão & $0^{\circ}$ & $0^{\circ}$ & $0^{\circ}$ & $0^{\circ}$ \\
\hline \multicolumn{5}{|l|}{ ANTEBRAÇO } \\
\hline Pronação & $25^{\circ}$ & $35^{\circ}$ & $20^{\circ}$ & $30^{\circ}$ \\
\hline Supinação & $0^{\circ}$ & $0^{\circ}$ & $0^{\circ}$ & $0^{\circ}$ \\
\hline \multicolumn{5}{|l|}{ PUNHO } \\
\hline Flexão & $5^{0}$ & $10^{\circ}$ & $10^{\circ}$ & $15^{\circ}$ \\
\hline Extensão & $5^{\circ}$ & $10^{\circ}$ & $5^{\circ}$ & $5^{0}$ \\
\hline
\end{tabular}

Fonte: elaboração dos autores.

(clique para voltar ao texto)

Tabela 2 - Goniometria de membros inferiores pré e pós-tratamento

\begin{tabular}{lcccc} 
Membro inferior & \multicolumn{2}{c}{ ESQUERDO } \\
Articulação e movimento & PRÉ & PÓS & PRÉ & PÓS \\
\hline QUADRIL & $80^{\circ}$ & $90^{\circ}$ & $80^{\circ}$ & $90^{\circ}$ \\
Flexão & $10^{\circ}$ & $15^{\circ}$ & $15^{\circ}$ & $20^{\circ}$ \\
Extensão & $30^{\circ}$ & $40^{\circ}$ & $30^{\circ}$ & $40^{\circ}$ \\
Abdução & $25^{\circ}$ & $30^{\circ}$ & $30^{\circ}$ & $40^{\circ}$ \\
Adução & $40^{\circ}$ & $40^{\circ}$ & $40^{\circ}$ & $40^{\circ}$ \\
Rotação Interna & $30^{\circ}$ & $35^{\circ}$ & $35^{\circ}$ & $40^{\circ}$ \\
Rotação Externa & & & & \\
JOELHO & $90^{\circ}$ & $100^{\circ}$ & $110^{\circ}$ & $115^{\circ}$ \\
Flexão & $0^{\circ}$ & $0^{\circ}$ & $0^{\circ}$ & $0^{\circ}$ \\
Extensão & & & & $0^{\circ}$ \\
\hline TORNOZELO & $0^{\circ}$ & $0^{\circ}$ & $0^{\circ}$ & $20^{\circ}$ \\
Dorsiflexão & $10^{\circ}$ & $15^{\circ}$ & $15^{\circ}$ & \\
Plantiflexão & & & $(c k$ para
\end{tabular}

Fonte: elaboração dos autores. 
Figura 1 - Força da musculatura de ombro direito e esquerdo antes e depois do tratamento

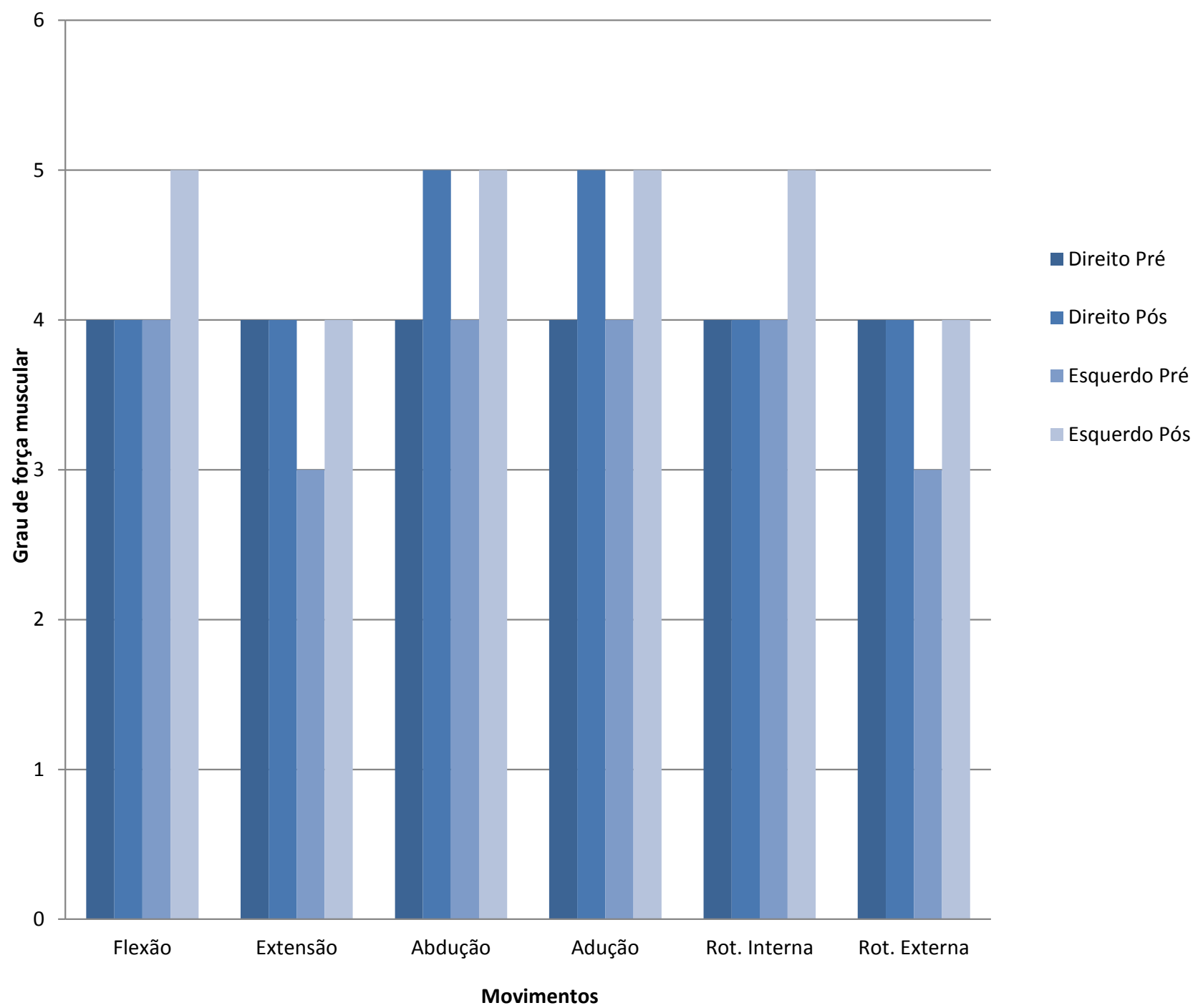

Fonte: elaboração dos autores.

(clique para voltar ao texto)

Figura 2 - Força da musculatura do cotovelo e punho direito e esquerdo antes e após o tratamento

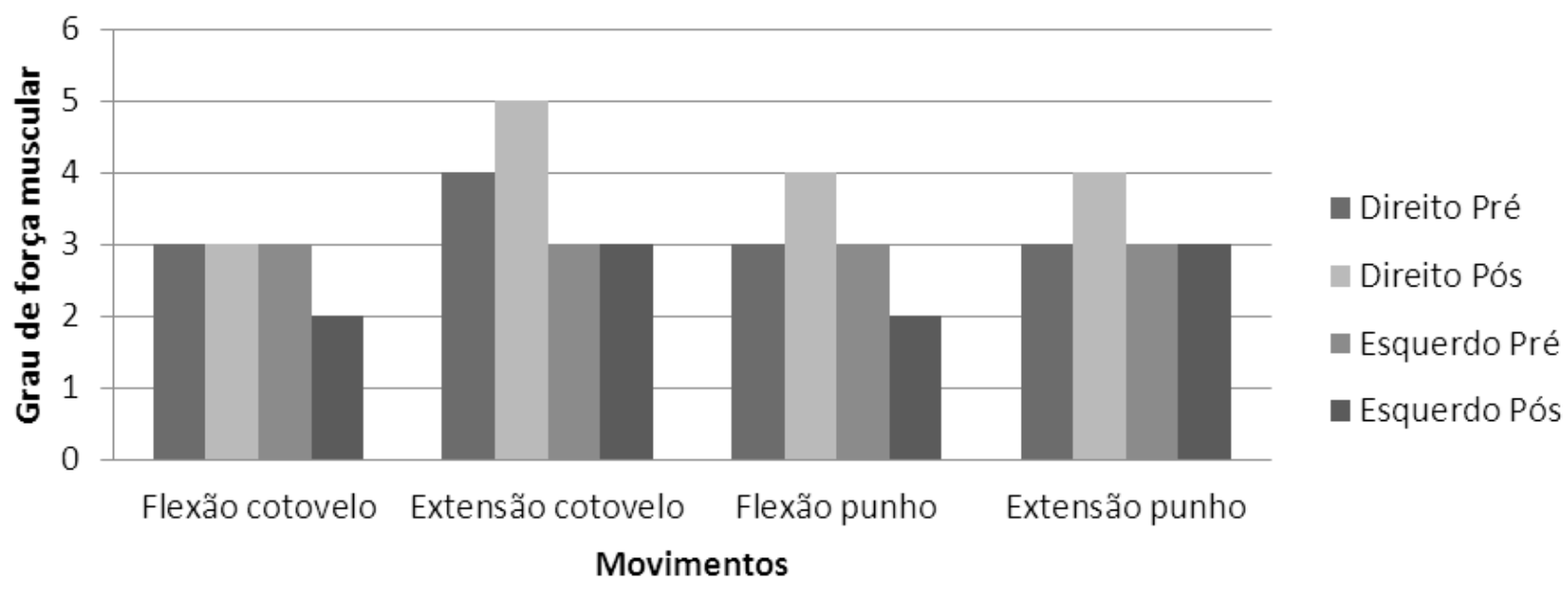

Fonte: elaboração dos autores.

(clique para voltar ao texto) 
Figura 3 - Força da musculatura de quadril antes e após o tratamento

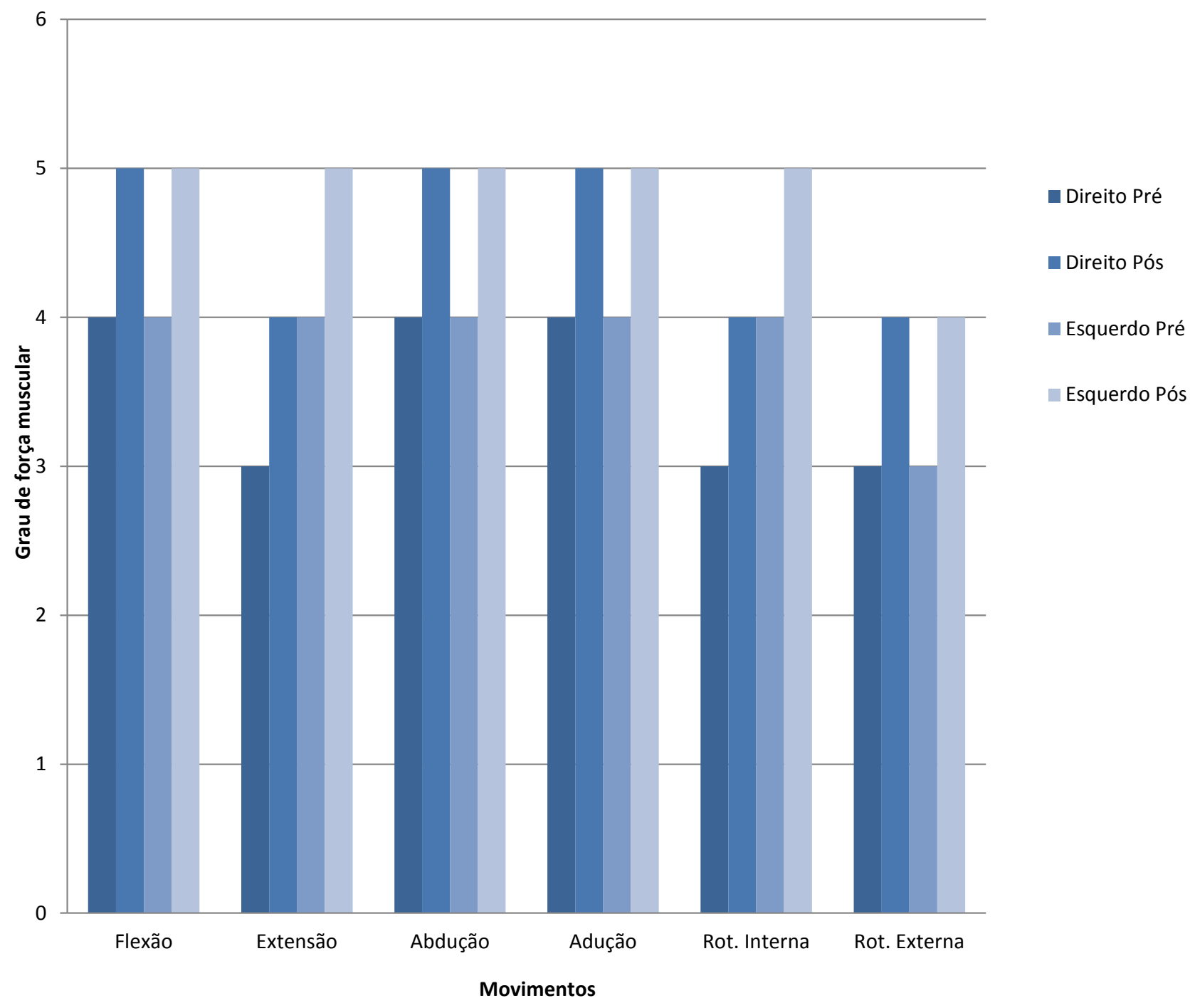

Fonte: elaboração dos autores.

(clique para voltar ao texto)

Figura 4 - Força dos músculos de joelho e tornozelo antes e após o tratamento

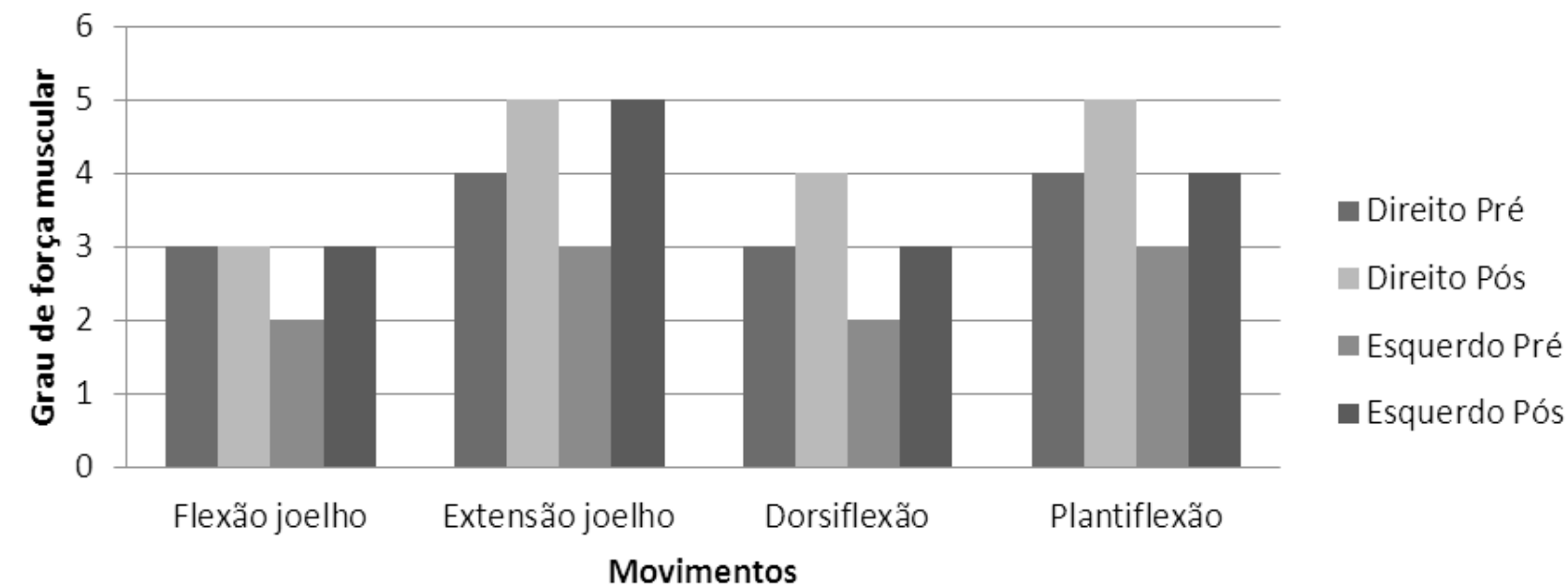

Fonte: elaboração dos autores.

(clique para voltar ao texto) 